\title{
O procedimento da arbitragem no juizado especial cível
}

The arbitration procedure in civil special court

\author{
Fabiane Grando ${ }^{1}$ (D) Amanda Caroline Schallenberger Schaurich ${ }^{2}$ (D) , Andressa Braga da Silva $^{3}$ (iD) e Gabriel \\ Bonetti Rubini ${ }^{4}$ \\ ${ }^{1}$ Universidade Estadual do Oeste do Paraná (UNIOESTE) e Universidade do Vale do Rio dos Sinos (UNISINOS), doutoranda, \\ mestre em Direito, graduada em Direito, email: gfabi2@yahoo.com.br \\ ${ }^{2}$ Universidade Estadual do Oeste do Paraná (UNIOESTE), graduada em Direito, amanda.schaurich@ @otmail.com \\ ${ }^{3}$ Universidade Estadual do Oeste do Paraná (UNIOESTE), graduada em Direito, email: andressa_bds@ @otmail.com \\ ${ }^{4}$ Universidade Estadual do Oeste do Paraná (UNIOESTE), graduado em Direito (2016), email: gabrielbonettirubini@gmail.com
}

\section{RESUMO}

A arbitragem é uma técnica extrajudicial para resolver conflitos em que os direitos patrimoniais sejam disponíveis e sua aplicação vem crescendo em nosso país devido às vantagens que proporciona. Ela já estava prevista em nossa legislação há muito tempo, mas ganhou força em 1996, quando foi regulada pela Lei ${ }^{\circ}$ 9.307. Mais recentemente, objetivando ampliar seu âmbito de incidência, houve uma série de mudanças no instituto trazidas pela Lei ${ }^{\circ} 13.129 / 15$. O objetivo do presente ensaio é tecer algumas reflexões sobre as formas alternativas de resolução de conflito que estão se consolidando no cenário jurídico brasileiro nas últimas décadas. Nessa perspectiva, o artigo aborda os seguintes aspectos: princípios que norteiam a arbitragem; distinções entre arbitragem, mediação e conciliação; os seus aspectos legais e o procedimento arbitral no Juizado Especial Cível. Pretende-se, ainda, por meio do emprego revisão bibliográfica e legislativa, apreciar o estado da arte da arbitragem e a efetividade desse instituto frente ao atual cenário jurídico brasileiro.

Palavras-chave: Arbitragem. Resolução de conflitos. Juizado Especial Cível.

\begin{abstract}
Arbitration is an extrajudicial technique to resolve conflicts in which property rights are available and its application has been growing in our country due to the advantages it provides. It was already foreseen in our legislation for a long time, but gained strength in 1996, when it was regulated by Law $\mathrm{n}^{\circ}$ 9.307. More recently, aiming to broaden its scope, there have been a number of changes to the institute brought by Law No. 13.129/15. The aim of this essay is to make some reflections on the alternative forms of conflict resolution that are consolidating in the Brazilian legal scenario in the last decades. From this perspective, the article addresses the following aspects: principles that guide arbitration; distinctions between arbitration, mediation and conciliation; its legal aspects and the arbitral proceedings in the Special Civil Court. It is also intended, through the use of bibliographic and legislative review, to appreciate the state of the art of arbitration and the effectiveness of this institute in the current Brazilian legal scenario.
\end{abstract}

Keywords: Arbitration. Conflict resolution. Special Civil Court.

Ciências Sociais Aplicadas em Revista, v. 20, n. 38, p. 23-40, semestral, janeiro-junho, 2020. 


\section{INTRODUÇÃO}

É inquestionável a existência de uma crescente delonga nas prestações jurisdicionais, principalmente no que se refere a uma ausência de efetiva promoção da paz social através da solução de contendas.

Considerando tal cenário, no intuito de reverter esta crescente morosidade, criou-se um meio alternativo ao Poder Judiciário para promover a solução de controvérsias, ao qual as partes (pessoas físicas ou jurídicas), livre e voluntariamente, se submetem, para obter soluções ágeis e de custo reduzido. Este processo é conhecido como arbitragem e traz resultados significativamente mais rápidos e vantajosos, tanto que chega a ser apontado, atualmente, como o melhor modo de solução de conflitos no seu âmbito de incidência.

Assim, o instituto da arbitragem vem ganhando cada vez mais espaço no direito brasileiro, representando meio alternativo de resolução de conflitos, que auxilia a suprir as dificuldades da população nas soluções dessas contendas e, consequentemente, a desobstruir o Poder Judiciário.

A arbitragem está prevista na Lei n ${ }^{\circ} 9307$ de 1996, a qual foi editada em 2015 buscando dar uma nova roupagem à arbitragem brasileira, prelecionando importantes princípios a nortear a arbitragem, tais como: devido processo legal, autonomia da vontade, imparcialidade e livre convencimento do árbitro, dentre outros.

Para que a arbitragem seja devidamente efetivada, as partes devem indicar árbitros, sendo estes considerados indivíduos civilmente capazes e de confiança de ambas as partes, que disponham de capacitação técnica para entender e decidir a problemática posta, sendo a decisão destinada a assumir a mesma eficácia da sentença judicial.

Diante disso, o presente processo visa delinear as diferenças entres os métodos alternativos de resolução de conflitos, além de investigar acerca da arbitragem e suas formas e, especialmente, sua efetividade.

\section{PRINCÍPIOS QUE NORTEIAM A ARBITRAGEM}

Os princípios jurídicos exteriorizam os valores de uma sociedade, guiando e orientado a construção legislativa. A Lei de Arbitragem encontra respaldo em diversos princípios jurídicos, o que é explicitado pelo art. $21, \S 2^{\circ}$ da mencionada norma, que assim preleciona:

Ciências Sociais Aplicadas em Revista, v. 20, n. 38, p. 23-40, semestral, janeiro-junho, 2020. 
Art. 21. A arbitragem obedecerá ao procedimento estabelecido pelas partes na convenção de arbitragem, que poderá reportar-se às regras de um órgão arbitral institucional ou entidade especializada, facultando-se, ainda, às partes delegar ao próprio árbitro, ou ao tribunal arbitral, regular o procedimento.

(...)

$\S 2^{\circ}$ Serão, sempre, respeitados no procedimento arbitral os princípios do contraditório, da igualdade das partes, da imparcialidade do árbitro e de seu livre convencimento.

Sendo assim, vale destacar de forma detalhada cada um destes.

Sobre o princípio do contraditório, cabe primeiramente pontuar que está diretamente relacionado com o direito de igualdade das partes, dando condições iguais durante todo o curso do processo. Assim como no processo judicial, na arbitragem, o julgador não pode proferir uma decisão sem antes ouvir a parte contrária, tendo em vista que o contraditório é uma garantia constitucional, conforme está previsto no art. $5^{\circ}$, inciso LV, da Constituição Federal:

Art. $5^{\circ}$ Todos são iguais perante a lei, sem distinção de qualquer natureza, garantindo-se aos brasileiros e aos estrangeiros residentes no País a inviolabilidade do direito à vida, à liberdade, à igualdade, à segurança e à propriedade, nos termos seguintes:

(...)

LV - aos litigantes, em processo judicial ou administrativo, e aos acusados em geral são assegurados o contraditório e ampla defesa, com os meios e recursos a ela inerentes;

Desta feita, entende-se que o procedimento arbitral corresponde a um diálogo entre as partes, já que o princípio do contraditório visa não apenas discutir razões da parte contrária, como também gerar a oportunidade de fazer a contraprova, gerando uma maior segurança jurídica na resolução das contendas.

O princípio da imparcialidade preza pela independência e neutralidade no julgamento da contenda. A imparcialidade do árbitro consiste na ausência de vínculos subjetivos com o processo, mantendo-se o julgador distante o necessário para conduzi-lo com isenção.

O princípio do livre convencimento ou persuasão racional consiste também na independência do árbitro de formar a sua opinião com a finalidade de decidir a lide, permitido formar sua livre convicção, apreciando provas e argumentos trazidos pelas partes, bem como outras que julgar oportunas para firmar o seu convencimento a respeito da contenda.

Esse princípio também é um dos princípios norteadores da Lei de arbitragem, já que permite que os árbitros, através da liberdade de apreciação das provas existentes, decidam. O livre convencimento não se confunde com arbítrio, sua decisão deverá ser motivada, não sendo permitido se desfazer de qualquer das provas, fatos e argumentos apresentados. 
Caso não esteja totalmente convencido dos fatos, tendo em vista que não pode se abster de julgar, é facultado ao árbitro a produção das provas que julgar necessárias para apurar a verdade.

Além destes princípios, destaca-se autonomia da vontade. O fato de o procedimento arbitral privilegiar a autonomia da vontade das partes, confere-lhe certa vantagem frente ao procedimento judicial litigioso.

Conforme Muniz (2004) apud Marques Filho (2016), tem-se que:

\begin{abstract}
A arbitragem, tendo sua origem num contrato, também encontra sua base neste princípio: o princípio da autonomia da vontade das partes de compor os conflitos submetendo-os aos árbitros. Princípio este que se manifesta pela liberdade que tem o indivíduo de extinguir o litígio surgido por ato de sua própria vontade, dentro dos casos permitidos e dos limites estabelecidos pela lei. A aplicação do princípio inclui a liberdade de escolher as diversas leis para reger o contrato, inserir as chamadas cláusulas de estabilização, excluir ou afastar qualquer direito nacional e escolher as normas aplicáveis (boa-fé, equidade, princípios gerais de direito, ou cláusulas de escolha negativa ou parcial de certo direito estatal).
\end{abstract}

Logo, há possibilidade de as partes pactuarem como transcorrerá a arbitragem, bem como qual lei será aplicada ao litígio, se deve ser usada ou não a equidade, quantos e quais serão os árbitros, expressando assim de forma plena a vontade de cada uma das partes, conforme preconiza o princípio.

\title{
3 DISTINÇÕES ENTRE ARBITRAGEM, CONCILIAÇÃO E MEDIAÇÃO
}

Assim como a arbitragem, a conciliação e a mediação também são meios alternativos de solução de litígios que se encontram cada vez mais presentes no nosso ordenamento jurídico, funcionando como meios extrajudiciais para a resolução de conflitos, garantindo aos cidadãos maior possibilidade de acesso e promoção de Justiça.

Segundo Pacheco (2017):

A conciliação, a Mediação e a Arbitragem tem desempenhado um papel dentro do novo Sistema Processual Civil, revelando a importância que conferiu o legislador brasileiro, na Lei $\mathrm{n}^{\circ}$ 13.105/15, aos Métodos Consensuais de Solução de Conflitos, como forma de descongestionar o judiciário visando uma cultura de paz e de direitos humanos.

Ainda sobre estes Métodos Consensuais de Solução de Conflitos, aduz o referido autor que:

(...) são instrumentos de afirmação da cidadania, consubstanciando-se como poderosa ferramenta a serviço da população, servindo para desburocratizar o judiciário, num efetivo pluralismo jurídico; no universo de uma nova Gestão Democrática do Poder Judiciário, no

Ciências Sociais Aplicadas em Revista, v. 20, n. 38, p. 23-40, semestral, janeiro-junho, 2020. 
sentido da plena concretização dos Direitos de cidadania e do fortalecimento da cultura de Direitos humanos (PACHECO, 2017).

O nosso ordenamento jurídico processual brasileiro incentiva a resolução de dissídios entre as partes, de modo que há um fortalecimento das técnicas de autocomposição, conforme preconiza o art. $3, \S 3^{\circ}$, do Código de Processo Civil, dispondo que:

$\S 3^{\circ}$ A conciliação, a mediação e outros métodos de solução consensual de conflitos deverão ser estimulados por juízes, advogados, defensores públicos e membros do Ministério Público, inclusive no curso do processo judicial.

Todavia, apesar da equivalente importância, faz-se necessário entender as diferenças entre cada um destes Métodos Consensuais de Solução de Conflitos, para que a melhor solução seja aplicada em cada caso concreto.

\title{
3.1 MEDIAÇÃO
}

A principal característica da mediação é proporcionar oportunidades para que as próprias partes em conflito tomem decisões para a melhor solução para o caso concreto.

Nesse meio alternativo, o intuito é a recuperação do diálogo entre as partes, de modo que são elas mesmo que decidem a questão, o que faz com que a mediação, assim como a negociação, seja considerada um instrumento de autocomposição.

Referente a este instituto, Antônio Gabriel Marques Filho (2016) afirma que "a mediação, por sua vez, através da figura do mediador - figura neutra e imparcial - apenas auxilia as partes a solucionar entre si o conflito, sem sugerir ou impor uma solução ou mesmo interferir nos termos do acordo".

Em complemento, Pacheco (2017) enfatiza que:

\begin{abstract}
O instrumento da mediação geralmente aplica-se aos conflitos de longa duração, frutos de relações mais estreitas, intensas e prolongadas. Em sua solução, busca-se a restauração da convivência, da harmonia, devendo o mediador, para tal, aprofundar-se no conhecimento das causas e origens do conflito entre as partes, analisando cuidadosamente as questões, os sentimentos, o contexto e buscando-se obter o reestabelecimento de uma convivência harmoniosa entre as partes.
\end{abstract}

Com efeito, na mediação, as partes recebem o auxílio de um mediador para a solução dos conflitos existentes entre elas, sendo que este possui como função atuar com neutralidade e 
imparcialidade, auxiliando as artes a se aproximarem e junto com elas identificar as questões do conflito, reestabelecendo a comunicação entre elas.

Em relação especificamente a esta função do mediador, dispõe o art. 165 , $\S 3^{\circ}$, do Código de Processo Civil:

$\S 3^{\circ} \mathrm{O}$ mediador, que atuará preferencialmente nos casos em que houver vínculo anterior entre as partes, auxiliará aos interessados a compreender as questões e os interesses em conflito, de modo que eles possam, pelo restabelecimento da comunicação, identificar, por si próprios, soluções consensuais que gerem benefícios mútuos.

Portanto, observamos que os principais atores da mediação são as próprias partes, sendo que neste instituto o objetivo é que ambas cheguem a um acordo por si, mantendo-se como autoras de suas próprias soluções.

\subsection{CONCILIAÇÃO}

A conciliação é um meio consensual de solução de conflitos em que as partes, por meio da ação de um terceiro alheio ao problema (o conciliador), chegam a um acordo, solucionando a controvérsia.

De acordo com Marques Filho (2016):

Por este método, busca-se uma solução por acordo entre as partes, tendo o conciliador o papel de propor ou sugerir soluções, embora sua função não permita nenhuma imposição compulsória de medidas ou decisão, ficando esta última inteiramente a critério das partes envolvidas na controvérsia.

Nessa linha, Tôrres (2016) ressalta que:

(...) a conciliação é vista como a forma de resolução de controvérsias na relação de interesses, onde será administrada por um conciliador indicado ou aceito pelas partes. Neste meio de resolução há a necessidade de um terceiro no intuito de aproximar as partes, formular propostas, assim como apontar vantagens e desvantagens.

Apesar de a conciliação ser um meio semelhante à mediação, o diploma processual civil estabelece uma distinção entre ambas as técnicas de autocomposição.

Conforme Freitas (2017):

A mediação é medida mais adequada nos casos em que tenha havido vínculo anterior entre as partes, a exemplo do que ocorre em matéria societária e de direito de família. $\mathrm{O}$ mediador, com o diálogo, paciência, simplicidade e esclarecimento constante, auxilia os interessados a compreender as questões e os interesses em conflito, de modo que eles

Ciências Sociais Aplicadas em Revista, v. 20, n. 38, p. 23-40, semestral, janeiro-junho, 2020. 
possam, pelo restabelecimento da comunicação, identificar, por si próprios, soluções consensuais que gerem benefícios mútuos.

Na mesma linha, Tôrres (2016) afirma que a diferença entre a conciliação e a mediação está na forma de abordagem que é realizada pelo terceiro, sendo que o conciliador pode apresentar propostas de solução de conflitos, enquanto o mediador não sugere nenhum tipo de solução, uma vez que sua função somente é facilitar o diálogo entre as partes.

Por fim, no tocante à função do conciliador, preconiza o art. $165, \S 2^{\circ}$, do Código de Processo Civil:

$\S 2^{\circ} \mathrm{O}$ conciliador, que atuará preferencialmente nos casos em que não houver vínculo anterior entre as partes, poderá sugerir soluções para o litígio, sendo vedada a utilização de qualquer tipo de constrangimento ou intimidação para que as partes conciliem.

Ou seja, pode-se notar que, no tocante à conciliação, ocorre a participação ativa do conciliador, diferentemente da participação do mediador.

\subsection{ARBITRAGEM}

A arbitragem, diferentemente da conciliação e da mediação, trata-se de um procedimento em que as partes escolhem uma pessoa capaz e de sua confiança para solucionar os conflitos, sendo este terceiro o árbitro. Nesta forma, ao contrário da conciliação e da mediação, as partes não possuem o poder de decisão (TORRES, 2016).

Importante ressaltar que há dois tipos de arbitragem: a arbitragem comum, regulamentada pela Lei da Arbitragem, e a arbitragem endoprocessual, que ocorre nos Juizados Especiais.

Esse meio de solução de conflitos é recorrido quando as partes não conseguem chegar a um resultado amigável por outro meio alternativo de solução de conflitos, mas também não querem enfrentar o meio tradicional de solução de litígio que é o processo judicial.

De acordo com Farias e Rosenvald (2012):

A arbitragem é o meio extrajudicial de solução de conflitos, por meio do qual árbitros resolvem divergências relativas a direitos patrimoniais disponíveis, com base na convenção de arbitragem pactuada entre as partes. Portanto, no seu espectro limitado não cabe discussão acerca de questões de estado, capacidade das pessoas, direitos difusos e matérias que reclamam a intervenção do Ministério Público. A arbitragem é adequada às hipóteses de cabimento de transação, caracterizando-se esta última, todavia, pela composição dos conflitos pelos próprios interessados, quando na arbitragem as partes, de comum acordo, transferem a solução da pendência a terceira pessoa (árbitro).

Ciências Sociais Aplicadas em Revista, v. 20, n. 38, p. 23-40, semestral, janeiro-junho, 2020. 
A arbitragem é, de certa forma, muito parecida com um processo judicial, uma vez que o conflito será decidido por um terceiro, de forma impositiva, que será o árbitro. No entanto, ao invés da morosidade do Judiciário, as partes dependem de uma Câmara Arbitral, na qual o julgador não será necessariamente um bacharel em direito, podendo ser também alguém com experiência na área relacionada ao conflito (JANNIS, 2016).

Conforme Muniz (2004) apud Marques Filho (2016):

(...) o procedimento arbitral não é formal como o judicial e pode ser, nos limites da Lei 9.307/1996, estabelecido pelas partes no que se refere à escolha dos árbitros e do direito material e processual que serão utilizados no conflito.

Cumpre destacar que este meio de solução de conflitos extrajudicial não sofrerá a intervenção do Poder Judiciário, salvo quando houver necessidade da utilização de força em razão do não atendimento às notificações por uma das partes envolvidas ou por terceiros. O próprio art. $22, \S 2^{\circ}$, da Lei ${ }^{\circ} 9307 / 96$, dispõe sobre o assunto que:

Art. 22. Poderá o árbitro ou o tribunal arbitral tomar o depoimento das partes, ouvir testemunhas e determinar a realização de perícias ou outras provas que julgar necessárias, mediante requerimento das partes ou de ofício.

$(\ldots)$

$\S 2^{\circ}$ Em caso de desatendimento, sem justa causa, da convocação para prestar depoimento pessoal, o árbitro ou o tribunal arbitral levará em consideração o comportamento da parte faltosa, ao proferir sua sentença; se a ausência for de testemunha, nas mesmas circunstâncias, poderá o árbitro ou o presidente do tribunal arbitral requerer à autoridade judiciária que conduza a testemunha renitente, comprovando a existência da convenção de arbitragem.

Nessa linha, entende-se que a arbitragem é uma alternativa confiável, na qual as partes escolhem o árbitro para dirimir a controvérsia existente. A prolação da sentença arbitral se dá de forma mais célere, sigilosa, e com maior simplicidade, sendo que sua decisão é proferida no máximo em 180 (cento e oitenta) dias, conforme disposto no art. 23, caput, da Lei $\mathrm{n}^{\circ}$ 9.307/96.

Em relação à arbitragem, este meio alternativo de solução de conflitos era disciplinado pela Lei $\mathrm{n}^{\circ}$ 9.307/96, vindo a ser alterada em 2015, pela Lei n $13.129 / 2015$, o que será melhor abordado no próximo tópico.

Ciências Sociais Aplicadas em Revista, v. 20, n. 38, p. 23-40, semestral, janeiro-junho, 2020. 


\title{
4 ASPECTOS LEGAIS DA ARBITRAGEM
}

Pode-se dizer que existe dois tipos de arbitragem: a judicial e a extrajudicial. De acordo com Felippe Borring Rocha (2019, p. 157), a principal diferença entre as duas é que "aquela tinha lugar quando o conflito de interesses já estava submetido à jurisdição estatal por meio de uma ação. De modo que a arbitragem judicial era tratada como um incidente ao processo judicial".

Como já exposto anteriormente, a arbitragem passou a ser regulamentada no Brasil em 1996, com a Lei $\mathrm{n}^{\circ}$ 9.307, momento no qual passou a ter uma maior visibilidade no país, passando a ser utilizada em diversas áreas do Direito, facilitando a resolução de diferentes tipos de conflito.

No entanto, após muita discussão, foi sancionada pela Presidência da República a Lei $\mathrm{n}^{\circ}$ 13.129/15, que trouxe alterações na Lei $\mathrm{n}^{\circ}$ 9.307/96, vindo a reformar a arbitragem, trazendo consigo uma série de novidades que modernizaram o instituto (ALMEIDA; NETO, 2015).

Ainda, salientam os autores:

\begin{abstract}
A ementa da supramencionada reforma expressa que esta altera as leis 9.307/96 e 6.404/76, para, em suma: ampliar o âmbito de aplicação da arbitragem; regulamentar sobre a escolha dos árbitros; prever a interrupção da prescrição pela instituição da arbitragem; estabelecer sobre a concessão de tutelas de urgência; dispor sobre a carta arbitral e a sentença arbitral e revogar dispositivos da lei 9.307/96 (ALMEIDA; NETO, 2015).
\end{abstract}

De qualquer forma, inobstante a existência das duas formas de arbitragem, Rocha (2019, p. 158) entende que as duas foram um fracasso, uma vez que, "em mais de duas décadas pesquisando sobre os Juizados Especiais somente foi possível localizar uma referência a um processo onde foi aplicada a arbitragem", procedimento este que ocorreu durante a vigência da antiga Lei dos Juizados de Pequenas Causa (Lei $\mathrm{n}^{\circ}$ 7.244/1984). Transcreve-se a ementa do processo encontrado por Rocha:

\footnotetext{
Mandado de segurança. Juízo Especial de Pequenas Causas. Laudo Arbitral. I - O Juizado Especial de Pequenas Causas, no caso, ao homologar laudo arbitral, não praticou ato ilegal ou arbitrário ensejador de segurança, cumprindo, ao contrário, seu dever de ofício. II Recurso ordinário desprovido" (STJ - 2 ${ }^{\mathrm{a}}$ Turma - RMS 262/GO - Rel. Min. Antônio de Pádua Ribeiro, j. em 02/09/1996).
}

Em que pese tal afirmação, para fins científicos, faz-se necessário abordar as principais inovações e alterações trazidas com o advento da reforma de Lei de Arbitragem. 


\subsection{PRINCIPAIS INOVAÇÕES COM O ADVENTO DA REFORMA DA LEI DE} ARBITRAGEM

Ao se questionar quanto aos objetivos da modificação da Lei de arbitragem, é certo que um deles, se não o principal, foi o de ampliar o seu âmbito de aplicação.

Justamente devido a esse objetivo que uma das principais mudanças trazidas pela Lei $\mathrm{n}^{\circ}$ $13.129 / 15$ foi a inclusão dos $\S \S 1^{\circ}$ e $2^{\circ}$, ao art. $1^{\circ}$ da Lei $n^{\circ} 9.307 / 96$, os quais passaram a permitir a utilização deste meio alternativo de solução de conflitos pela administração pública direta e indireta.

Os mencionados parágrafos dispõem que:

$\S 1^{o}$ A administração pública direta e indireta poderá utilizar-se da arbitragem para dirimir conflitos relativos a direitos patrimoniais disponíveis.

$\S 2^{\mathrm{o}}$ A autoridade ou o órgão competente da administração pública direta para a celebração de convenção de arbitragem é a mesma para a realização de acordos ou transações.

Oportuno esclarecer que a prática de arbitragem por parte da administração pública indireta já era aceita pela maioria da doutrina, apesar de não regulamentada anteriormente. Nesse sentido, destaca-se precedente do Supremo Tribunal Federal:

INCORPORAÇÃO, BENS E DIREITOS DAS EMPRESAS ORGANIZAÇÃO LAGE E DO ESPOLIO DE HENRIQUE LAGE. JUÍZO ARBITRAL. CLÁUSULA DE IRRECORRIBILIDADE. JUROS DA MORA. CORREÇÃO MONETÁRIA. 1. LEGALIDADE DO JUÍZO ARBITRAL, QUE O NOSSO DIREITO SEMPRE ADMITIU E CONSAGROU, ATÉ MESMO NAS CAUSAS CONTRA A FAZENDA. PRECEDENTE DO SUPREMO TRIBUNAL FEDERAL. 2. LEGITIMIDADE DA CLÁUSULA DE IRRECORRIBILIDADE DE SENTENÇA ARBITRAL, QUE NÃO OFENDE A NORMA CONSTITUCIONAL. 3. JUROS DE MORA CONCEDIDOS, PELO ACÓRDÃO AGRAVADO, NA FORMA DA LEI, OU SEJA, A PARTIR DA PROPOSITURA DA AÇÃO. RAZOAVEL INTERPRETAÇÃO DA SITUAÇÃO DOS AUTOS E DA LEI N. 4.414, DE 1964. 4. CORREÇÃO MONETÁRIA CONCEDIDA, PELO TRIBUNAL A QUO, A PARTIR DA PUBLICAÇÃO DA LEI N. 4.686, DE 21.6.65. DECISÃO CORRETA. 5. AGRAVO DE INSTRUMENTO A QUE SE NEGOU PROVIMENTO. (STF - AI 52181 / GB - GUANABARA - RELATOR MINISTRO BILAC PINTO. Data de Julgamento: 14/11/73). (sem grifos no original).

Além disso, foi alterado também o $\$ 4^{\circ}$ do art. 13 da mencionada Lei de arbitragem, no tocante à lista de árbitros, com a seguinte redação:

$\S 4$ o As partes, de comum acordo, poderão afastar a aplicação de dispositivo do regulamento do órgão arbitral institucional ou entidade especializada que limite a escolha do árbitro único, coárbitro ou presidente do tribunal à respectiva lista de árbitros, autorizado o controle da escolha pelos órgãos competentes da instituição, sendo que, nos

Ciências Sociais Aplicadas em Revista, v. 20, n. 38, p. 23-40, semestral, janeiro-junho, 2020. 
casos de impasse e arbitragem multiparte, deverá ser observado o que dispuser o regulamento aplicável.

Essa mudança revela a faculdade das partes em escolher outros árbitros, distintos dos credenciados pelo órgão arbitral institucional, privilegiando, desta forma, a autonomia das partes (ALMEIDA; NETO, 2015).

A Lei $\mathrm{n}^{\circ}$ 13.129/15 também veio a alterar a Lei $\mathrm{n}^{\circ}$ 6.404/76 (Lei das Sociedades Anônimas), ao inserir o art. 136-A na referida espécie normativa. Conforme aduzem Almeida; Neto (2015) “o novo dispositivo regula a inserção de convenção de arbitragem no estatuto social, obrigando todos os acionistas, quando observado o quórum qualificado do artigo 136 da mesma lei”.

Complementam ainda os referidos autores que:

Antes da aprovação da nova lei, o $§ 3^{\circ}$ do artigo 109 da lei das Sociedades Anônimas permitia a inclusão da convenção arbitral no estatuto social. Todavia, a falta de uma definição legal sobre a vinculação dos acionistas era utilizada como argumento por aqueles contrários à utilização da arbitragem nos casos em que o acionista não tivesse aprovado a respectiva cláusula compromissória. Tal controvérsia foi dissipada com a inclusão do artigo 136-A. (ALMEIDA; NETO, 2015).

No tocante à interrupção da prescrição, a Lei de arbitragem trouxe a seguinte inovação:

Quanto à interrupção da prescrição, tal inovação vem para dirimir a questão, não deixando margem a diferentes interpretações, de modo que as alterações realizadas no artigo 19 da lei em comento, as quais acresceram dois parágrafos ao referido artigo, regulamentam que a instituição da arbitragem interrompe a prescrição, retroagindo à data do requerimento de sua instauração. (ALMEIDA; NETO, 2015)

Ainda, passou-se a ser regulamentada pela Lei $\mathrm{n}^{\circ} 13.129 / 15$ a sentença parcial, uma vez que o art. $23, \S 1^{\circ}$, da referida Lei, expressa a possibilidade de ser proferida sentença parcial pelos árbitros.

Outra importante alteração foi a nova redação trazidas nos arts. 35 e 39 da mesma Lei, que passaram a estabelecer que compete ao STJ e não mais ao STF a homologação ou denegação de sentença arbitral estrangeira. Tal alteração formalizou uma prática que já vinha sendo utilizada nos últimos anos, uma vez que a Emenda Constitucional 45 transferiu a competência do STF para o STJ para processar e julgar sentenças estrangeiras (ALMEIDA; NETO, 2015).

Também a carta arbitral trouxe modernização e avanço da Lei, com a inclusão do art. 22-C na Lei ${ }^{\circ} 13.129 / 15$. No tocante ao assunto, salienta-se que: 
(...) a lei 13.129/15 trouxe a inovação da carta arbitral com a inclusão do artigo 22-C, que nada mais é que um novo veículo de cooperação com o Poder Judiciário, caracterizando uma modernização e avanço da lei. Através da carta arbitral, os árbitros poderão requerer a colaboração do Poder Judiciário em medidas que demandem um ato estatal de força à distância para, por exemplo, o cumprimento de tutelas emergenciais (ALMEIDA; NETO, 2015).

Por fim, importante esclarecer que a Lei $n^{\circ}$ 13.129/15 não foi sancionada integralmente, uma vez que a Presidência da República vetou a alteração do $\S 2^{\circ}$ e a inclusão dos $\S \S 3^{\circ}$ e $4^{o}$ ao art. $4^{o}$ da Lei de arbitragem, no que se refere ao conceito de cláusula compromissória, os quais previam que ficariam permitidas, limitadamente, a inclusão dessas cláusulas em contratos de trabalho e em contratos de adesão relacionados a consumo.

\section{O PROCEDIMENTO ARBITRAL NO JUIZADO ESPECIAL CÍVEL}

A arbitragem no Juizado Especial Cível é regida pela Lei n ${ }^{\circ}$ 9.099/95, em seus arts. 24 a 26, e pela Lei $n^{\circ}$ 9.307/96, que não apresenta conflito em relação aos artigos da Lei dos Juizados Especiais já mencionados.

Como já citado, a arbitragem prevista no procedimento do Juizado Especial Cível é a endoprocessual que, conforme disposto no art. 24 da Lei $n^{\circ}$ 9.099/95, tem vez após a tentativa de conciliação: "Não obtida a conciliação, as partes poderão optar, de comum acordo, pelo juízo arbitral, na forma prevista nesta Lei".

Dessa forma, estando as partes de comum acordo, o juízo arbitral irá se instaurar, mediante escolha do árbitro pelas partes. Importante ressaltar que a arbitragem pode ser realizada no mesmo dia da audiência de conciliação ou, caso o árbitro escolhido não esteja presente, será designada audiência de instrução. É o que dispõe o $\$ 1^{\circ}$ do art. 24:

$\S 1^{\text {o }}$ O juízo arbitral considerar-se-á instaurado, independentemente de termo de compromisso, com a escolha do árbitro pelas partes. Se este não estiver presente, o Juiz convocá-lo-á e designará, de imediato, a data para a audiência de instrução.

Ademais, conforme previsão do $\S 2^{\circ}$ do art. 24, “o árbitro será escolhido dentre os juízes leigos". A figura do Juiz Leigo tem grande importância no procedimento do Juizado Especial Cível, sendo prevista no art. $7^{\circ}$ da Lei $n^{\circ}$ 9.099/95. O referido dispositivo regula que será necessário, no mínimo, 5 (cinco) anos de experiência na área de advocacia para que o advogado possa ser 
recrutado como Juiz Leigo, ficando impedido de exercer a advocacia perante o Juizado Especial durante o exercício de suas funções de Juiz Leigo.

Tal qual a decisão proferida por Juiz Leigo, o laudo arbitral deve ser submetido ao Juiz Togado para homologação, podendo ser quando do término da instrução ou nos cinco dias subsequentes a esta. É o que prevê o art. 26 da Lei dos Juizados Especiais Cíveis Estaduais: “ao término da instrução, ou nos cinco dias subsequentes, o árbitro apresentará o laudo ao Juiz togado para homologação por sentença irrecorrível". Neste caso, diferente da decisão homologatória prevista no art. 40 da referida Lei, a sentença é irrecorrível, regra prevista também no enunciado ${ }^{\circ}$ 7 do FONAJE: “A sentença que homologa o laudo arbitral é irrecorrível”.

A Lei n ${ }^{\circ} 9.099 / 95$ ainda prevê que o árbitro deverá conduzir o processo seguindo os mesmos critérios do Juiz, previstos nos art. $5^{\circ}$ e $6^{\circ}$ da referida norma:

Art. $5^{\circ}$ O Juiz dirigirá o processo com liberdade para determinar as provas a serem produzidas, para apreciá-las e para dar especial valor às regras de experiência comum ou técnica.

Art. $6^{\circ} \mathrm{O}$ Juiz adotará em cada caso a decisão que reputar mais justa e equânime, atendendo aos fins sociais da lei e às exigências do bem comum.

Tal previsão está disposta no art. 25 da Lei, in verbis: "o árbitro conduzirá o processo com os mesmos critérios do Juiz, na forma dos arts. $5^{\circ}$ e $6^{\circ}$ desta Lei, podendo decidir por equidade".

Todavia, o procedimento da arbitragem pode não interessar às partes, de modo que poderá ser designada data para a realização de uma nova audiência, de instrução e julgamento, ou ainda a referida solenidade pode ser realizada imediatamente, nos termos do art. 27 da lei que rege os Juizados Especiais:

Art. 27. Não instituído o juízo arbitral, proceder-se-á imediatamente à audiência de instrução e julgamento, desde que não resulte prejuízo para a defesa.

Parágrafo único. Não sendo possível a sua realização imediata, será a audiência designada para um dos quinze dias subsequentes, cientes, desde logo, as partes e testemunhas eventualmente presentes.

Cumpre informar que é comum, quando da abertura a audiência de instrução e julgamento, o juiz togado ou leigo que conduzirá essa solenidade incentivar, novamente, a obtenção de um acordo entre as partes, em observância aos princípios que regem esse microssistema especializado. 
Em que pese a previsão do procedimento arbitral na Lei n ${ }^{\circ}$ 9.099/95, há entendimentos em sentido contrário, criticando a arbitragem no rito do Juizado Especial. Nesse sentido, é o entendimento de Corrêa (2008):

Sendo assim, com a breve explicação acima desenhada fica complicada a defesa da arbitragem nos Juizados Especiais, que seria realizada por um advogado com mais de cinco anos de experiência, mostrando que o conhecimento técnico do árbitro seria o mesmo do Juiz, apenas o conhecimento jurídico. Este fato levanta outra questão: que diferença teria a decisão tomada por um Juiz leigo, atuando como Juiz leigo, da decisão tomada, pelo mesmo Juiz leigo atuando como árbitro? Talvez a única e triste diferença seja a de que sua decisão como árbitro seja irrecorrível e sua decisão como Juiz leigo poderá ser revista pela Turma Recursal.

Além disso, outro obstáculo à instauração do procedimento arbitral nos Juizados Especiais, é o de que, como exigir dos jurisdicionados, na sua maioria pessoas humildes e de baixa instrução, que por meio de simples acesso aos quadros de juízes leigos dos Juizados Especiais, confiem nestes árbitros (juízes leigos) de forma a lhe darem o direito de decidir suas demandas sem uma garantia efetiva de isonomia e imparcialidade que o Estado, pelo menos em tese lhes proporciona? Parece que, no caso dos Juizados Especiais torna-se inviável e indefensável tal prática.

Para Miranda; Cordeiro (2008), o procedimento arbitral previsto nos arts. 24 a 26 da Lei n $^{\circ}$ 9.099/95 se constitui letra morta, considerando sua baixa aplicabilidade na prática:

É fato que, majoritariamente, a doutrina silencia-se quanto às pesquisas e escritos a respeito da arbitragem, de modo que se torna de grande dificuldade conseguir material científico-jurídico que trate especificamente desse instituto previsto na Lei no ${ }^{\circ}$ 9.099/95. Esse árbitro, que, em tese, julgaria o conflito quando as partes optassem por seu juízo, sendo nessa hipótese investido de poderes como os do juiz togado, de fato não existe na grande maioria dos juizados especiais instalados nas comarcas ou circunscrições judiciárias.

Dessa maneira, embora haja previsão legal sobre a faculdade das partes optarem pelo juízo arbitral, tal disposição de lei pode ser caracterizada como letra morta, ou seja, expressão que apenas existe no ordenamento jurídico sem aplicabilidade no mundo fático.

Todavia, há quem defenda sua efetividade, como Cunha (2014):

A mediação (ou conciliação) endoprocessual e a arbitragem endoprocessual, parecem-nos, são propostas que merecem acurada reflexão pelos fins sociais a que se propõem, sendo tratada corretamente pela Lei $n^{\circ} 7.244 / 84$ e repetida na Lei $n^{\circ} 9.099 / 95$, devendo ser estendidas a todos os demais processos, e não como parece ocorreu na recente lei de arbitragem, que afasta o cidadão do acesso ao Poder Judiciário.

(...)

A arbitragem, com a qual, em uma década de Magistratura, não nos deparamos com um único caso, no modelo do CPC, nos Juizados Especiais é uma realidade que alcança no período o expressivo número de 1948 casos.

Em que pese a controvérsia existente, a arbitragem está efetivamente prevista no rito do Juizado Especial Cível, podendo ser aplicada quando infrutífera a conciliação entre as partes. 
Porém, na prática, é difícil se verificar a aplicação do instituto, uma vez que se tornou obsoleto - não nos olvidamos que a Lei dos Juizados Especiais é de 1995, mas, assim como a sociedade muda, os institutos também devem ser melhorados, de acordo com o momento atual.

Assim sendo, a arbitragem endoprocessual pode, de fato, ser considerado letra morta, havendo a possibilidade de substituição pela arbitragem extraprocessual, instituto contemporâneo, considerando a atualização em 2015, e mais utilizado nos dias atuais.

\section{CONSIDERAÇÕES FINAIS}

Diante de todo o exposto, verifica-se que o instituto da arbitragem tem grande importância em nosso ordenamento jurídico, sendo utilizado como tentativa de diminuir o número de demandas judiciais que se alastram por longo tempo, juntamente com a mediação e a conciliação. Estas, embora parecidas com a arbitragem, não se confundem, conforme explanado anteriormente.

Ademais, há uma série de princípios, previstos na própria Lei da Arbitragem, que devem ser analisados quando da instauração do procedimento arbitral.

No tocante ao Juizado Especial Cível, vislumbrou-se que, embora prevista no procedimento instituído pela Lei no 9.099/95, a arbitragem endoprocessual não é amplamente aceita, havendo divergências de entendimento quanto à aplicação do instituto no Juizado Especial.

De toda forma, resta evidenciada a importância do procedimento arbitral, de forma geral, como método de solução de conflitos, a fim de evitar longas demandas processuais.

Porém, pensando-se apenas na arbitragem endoprocessual, prevista na Lei dos Juizados Especiais, diante de sua baixa aplicabilidade na prática, verifica-se que pode ser considerada letra morta e, eventualmente, até mesmo suprimida pela arbitragem comum (extraprocessual), prevista na Lei de Arbitragem.

Sob esta ótica, conclui-se que seria interessante uma reformulação do procedimento arbitral endoprocessual, para que fosse aplicado, em seu lugar, a arbitragem extrapocessual prevista na Lei de Arbitragem, de modo a garantir a efetividade do instituto e, até mesmo, do judiciário.

\section{REFERÊNCIAS}

ALMEIDA, André de; NETO, Ruy Menezes. Principais alterações à lei de arbitragem. Disponível em: <http://www.migalhas.com.br/dePeso/16,MI224473,51045Principais+alteracoes+a+lei+de+arbitragem>. Acesso em 12 ago. 2018. 
BARBOSA, Maiana Vaz do Amaral Barbosa. A arbitragem na administração pública. Disponível em: <http://www.egov.ufsc.br/portal/sites/default/files/anexos/20057-20058-1PB.pdf >. Acesso em 13 ago. 2018.

BRASIL. Portal da Legislação do Governo Federal. Lei N 9.099, de 26 de setembro de 1995. Disponível em: <http://www.planalto.gov.br/ccivil_03/Leis/L9099.htm>. Acesso em 07 ago. 2018.

CASSANTE, Guilherme Vida Leal. Os princípios aplicáveis na Arbitragem e suas definições. Disponível em: <https://guisambareando.jusbrasil.com.br/artigos/254469363/os-principiosaplicaveis-na-arbitragem-e-suas-definicoes>. Acesso em 13 ago. 2018.

CONIMA. Conselho Nacional das Instituições de Mediação e Arbitragem. A conciliação e a mediação no CPC/2015. Disponível em: <http://www.conima.org.br/arquivos/15990>. Acesso em 10 ago. 2018.

CONSELHO NACIONAL DE JUSTIÇA. Conciliação e Mediação. Disponível em: <http://www.cnj.jus.br/programas-e-acoes/conciliacao-e-mediacao-portal-da-conciliacao>.

Acesso em 10 ago. 2018.

CORDEIRO, Carlos José; MIRANDA, Lara Caroline. Dos Institutos da Conciliação e da Arbitragem na Lei dos Juizados Especiais Estaduais Cíveis: Estudo de sua relevância para a solução de litígios. Disponível em: <www.seer.ufu.br/index.php/horizontecientifico/article/download/4202/3144>. Acesso em 07 ago. 2018 .

CORREAA, Guilherme Augusto Bittencourt. "Juizados Especiais Cíveis Estaduais: Acesso à Justiça?”. Revista Eletrônica do CEJUR, Curitiba-PR, a. 2, v. 1, n. 3, ago./dez. 2008, Disponível em: <https://revistas.ufpr.br/cejur/article/download/16759/11145>. Acesso em 07 ago. 2018.

CUNHA, J. S. Fagundes. Da mediação e da arbitragem endoprocessual. Disponível em: < http://inseer.ibict.br/cafsj/index.php/cafsj/article/download/49/pdf.>. Acesso em 07 ago. 2018.

DEFENSORIA PÚBLICA DE MATO GROSSO. Saiba a diferença entre mediação, conciliação e arbitragem. Disponível em: <https://dp-mt.jusbrasil.com.br/noticias/3116206/saiba-a-diferencaentre-mediacao-conciliacao-e-arbitragem>. Acesso em 04 ago. 2018.

FARIAS, Cristiano Chaves de; ROSENVALD, Nelson. Curso de Direito Civil. Famílias. 4. ed. rev. atual. e ampl. Salvador: Jus Podivm, 2012. Acesso em 28 ago. 2019.

FONAJE. Enunciados. Disponível em: <http://www.amb.com.br/fonaje/?p=32>. Acesso em 07 ago. 2018.

GARCIA, Daniele. Juizados Especiais Cíveis e a falha na aplicabilidade dos princípios em relação as audiências de conciliação, ante a nova realidade dos números processuais dos Juizados Especiais. Disponível em: <http://www.facnopar.com.br/conteudo-arquivos/arquivo2017-06-14-14974725843453.pdf>. Acesso em 07 ago. 2018. 
JANNIS, André. O que são meios alternativos de resolução de conflitos. Disponível em: $<$ http://www.politize.com.br/meios-alternativos-resolucao-de-conflitos-o-que-sao/>. Acesso em 10 ago. 2018.

JURÍDICO CERTO. Conciliação, Mediação e arbitragem: entenda, definitivamente, a diferença. Disponível em: <https://blog.juridicocerto.com/2018/03/conciliacao-mediacao-e-arbitragementenda-definitivamente-a-diferenca.html >. Acesso em 04 ago. 2018.

LEÇA, Laíse Nunes Mariz. Conciliação nos Juizados Especiais Cíveis. Disponível em: <http://www.ambitojuridico.com.br/site/index.php?n_link=revista_artigos_leitura\&artigo_id=110 14>. Acesso em 07 ago. 2018.

MARQUES FILHO, Antonio Gabriel. Arbitragem, conciliação e mediação: métodos extrajudiciais efetivos de resolução de conflitos. Disponível em: <https://marq4.jusbrasil.com.br/artigos/363749107/arbitragem-conciliacao-e-mediacao-metodosextrajudiciais-efetivos-de-resolucao-de-conflitos>. Acesso em 10 ago. 2018.

MELO, Raphael Matos Albuquerque de. A lei da arbitragem e a sua aplicabilidade. Disponível em:

<http://www.fespfaculdades.com.br/painel/uploads/arquivos/TCCArt.\%20Cient\%EDfico\%20$\% 20$ A $\% 20$ Lei $\% 20 \mathrm{de} \% 20$ Arbitragem $\% 20 \mathrm{e} \% 20 \mathrm{a} \% 20$ sua\%20aplicabilidade.pdf $>$. Acesso em 13 ago. 2018.

NETO, Elias Marques de Medeiros; RIBEIRO, Natalia Ruiz; TUON, Carolina de Souza. Alterações advindas da reforma da lei de arbitragem - lei 13.129/15. Disponível em: <http://www.migalhas.com.br/dePeso/16,MI224595,51045-

Alteracoes+advindas+da+reforma+da+lei+de+Arbitragem+lei+1312915>. Acesso em: 12 ago. 2018.

PACHECO, Marcelo Isacksson. Os meios alternativos de solução de conflitos e o acesso à justiça no âmbito do novo CPC, Lei 13.105/15. Disponível em: $<$ https://pachecoap.jusbrasil.com.br/artigos/434925590/os-meios-alternativos-de-solucao-deconflitos-e-o-acesso-a-justica-no-ambito-do-novo-cpc-lei-13105-15>. Acesso em 05 ago. 2018.

RIBEIRO, Ana Claudia Rodrigues Nerosky; SUXBERGER, Antônio Henrique Graciano. "Arbitragem como meio de solução de conflitos nos contratos da Administração Pública: limites, forma e momento de previsão". Revista de Estudos e Pesquisas Avançadas do Terceiro Setor, Brasília, V. 4, $\mathrm{n}^{\mathrm{o}}$ 2, p.454-476, Jul-Dez, 2017. Disponível em: $<$ https://portalrevistas.ucb.br/index.php/REPATS/article/view/8387/pdf>. Acesso em 13 ago. 2018.

ROCHA, Felippe Borring. "A necessária reformulação do procedimento arbitral nos Juizados Especiais Cíveis", Revista Interdisciplinar de Direito, v. 17, n. 1, pp.155-166, jan./jun. 2019. Disponível em: <https://revistas.faa.edu.br/index.php/FDV/article/view/752/570>. Acesso em 15 set. 2019.

TÔRRES, Lorena Lucena. Mediação e arbitragem no novo CPC: as diferenças e ganhos com as novas técnicas de resolução de conflitos. Disponível em: 
$<$ https://lucenatorres.jusbrasil.com.br/artigos/373250699/mediacao-e-arbitragem-no-novo-cpc-asdiferencas-e-ganhos-com-as-novas-tecnicas-de-resolucao-de-conflitos>. Acesso em 04 ago. 2018.

VILAS-BÔAS, Renata Malta. Os Princípios Norteadores do Direito e a Arbitragem. Disponível em: <http://sisnet.aduaneiras.com.br/lex/doutrinas/arquivos/arbitragem.pdf>. Acesso em 13 ago. 2018 . 